\title{
Inter-Turn Stator Winding Fault Diagnosis in Three-Phase Induction Motors, by Park's Vector Approach
}

\author{
A. J. Marques Cardoso \\ Associate Member, IEEE
}

\author{
S. M. A. Cruz \\ Student Member, IEEE
}

D. S. B. Fonseca
Non-Member, IEEE

\author{
Universidade de Coimbra, Departamento de Engenharia Electrotécnica \\ Polo II - Pinhal de Marrocos \\ P-3030 Coimbra, Portugal
}

\begin{abstract}
The subject of on-line detection and location of inter-turn short circuits in the stator windings of three-phase induction motors is discussed, and a noninvasive approach, based on the computer-aided monitoring of the stator current Park's Vector, is introduced. Experimental results, obtained by using a special fault producing test rig, demonstrate the effectiveness of the proposed technique, for detecting inter-turn stator winding faults in operating three-phase induction machines. On-site tests conducted in a power generation plant, using the diagnostic instrumentation system developed, are also reported.
\end{abstract}

Keywords: Induction motors, fault diagnosis, stator winding faults, insulation failure.

\section{INTRODUCTION}

Previous research, concerning the use of Park's Vector Approach, has demonstrated the effectiveness of this noninvasive technique for diagnosing malfunctions, such as, single-phasing, open wound-rotor faults, airgap eccentricity and rotor cage faults, in operating three-phase induction motors [1]-[3].

Unfortunately, an induction motor can fail due to other fault mechanisms [4]. Stator winding failures, which can occur due to a combination of thermal, electrical, mechanical and environmental stresses that act on the stator [5], are found to be one of the major causes of motor failure [4].

The subject of on-line detection of inter-turn short circuits in the stator windings of three-phase induction motors has been addressed by some researchers. Techniques such as those based on the spectral analysis of the motor current [6], frame vibration [7], [8], or the axial leakage flux [7], [9], have been proposed. An on-line method to detect incipient failure of turn insulation in random-wound motors, based on an indicator termed the effective negative-sequence impedance which is computed from the voltage and current phasors at the motor

PE-1166-EC-0-10-1997 A paper recommended and approved by the IEEE Electric Machinery Committee of the IEEE Power Engineering Society for publication in the IEEE Transactions on Energy Conversion. Manuscript submitted August 27, 1997; made available for printing October 7, 1997. terminals is also described in [10].

This paper introduces a new approach, based on the computer-aided monitoring of the motor current Park's Vector representation, for diagnosing inter-turn stator winding faults in operating three-phase induction machines.

\section{PARK'S VECTOR APPROACH}

As a function of mains phase-variables $\left(i_{A}, i_{B}, i_{C}\right)$ the motor current Park's Vector components $\left(i_{D}, i_{Q}\right)$ are

$$
\begin{aligned}
& i_{D}=(\sqrt{2} / \sqrt{3}) i_{A}-(1 / \sqrt{6}) i_{B}-(1 / \sqrt{6}) i_{C} \\
& i_{Q}=(1 / \sqrt{2}) i_{B}-(1 / \sqrt{2}) i_{C} .
\end{aligned}
$$

Under ideal conditions, the three-phase currents lead to a Park's Vector with the following components:

$$
\begin{aligned}
& i_{D}=(\sqrt{6} / 2) i_{M} \sin (\omega t) \\
& i_{Q}=(\sqrt{6} / 2) i_{M} \sin (\omega t-\pi / 2)
\end{aligned}
$$

where

$i_{M}$ maximum value of the supply phase current (A)

$\omega$ angular supply frequency $(\mathrm{rad} / \mathrm{s})$

$t$ time variable (s).

The corresponding representation is a circular locus centered at the origin of the coordinates.

Under abnormal conditions, (3) and (4) are no longer valid and consequently the observed picture differs from the reference pattern.

The operating philosophy of the Park's Vector Approach is thus based on identifying unique signature patterns in the figures obtained, corresponding to the motor current Park's Vector representation.

\section{LABORATORY TESTS}

\section{A. Details of the Test Rig}

The test motor used in the experimental investigation of the occurrence of inter-turn stator winding faults was a three-phase, $50 \mathrm{~Hz}$, 4-pole, $15 \mathrm{~kW}$, SEW-EURODRIVE ${ }^{\oplus}$ squirrel cage induction machine, type DV160L4, rated at $400 \mathrm{~V}, 29.5 \mathrm{~A}$ and $1450 \mathrm{rpm}$. 
The stator winding has been modified by addition of a number of tappings connected to the stator coils, for each of the three phases. The other end of these external wires is connected to an enlarged motor terminal box, allowing for the introduction of shorted turns at several locations in the stator winding. The motor has two parallel paths per phase and a total of 147 turns per path/phase. The stator winding arrangement is illustrated in Fig. 1 and the location of the tappings for one of the motor phases (phase $A$ ) is shown in Fig. 2.

The diagnostic instrumentation system used basically comprises a Macintosh $\mathrm{II}^{\circledR}$ microcomputer supporting a Data Translation data acquisition board, model DT $2228^{\oplus}$, connected to three clip-on current probes, type Chauvin Arnoux PAC $500^{\circledR}$, through a preconditioning module. Further details of this diagnostic instrumentation system can be found in [2].

\section{B. Experimental Results}

The motor was initially tested, in the absence of faults, in order to verify the current Park's Vector reference pattern. Subsequently, shorted turns were introduced in the stator winding and current Park's Vector examined as a function of the degree of severity of the fault and its location. The motor was delta connected and a shorting resistor was used, whose value was chosen so as to create an effect strong enough to be easily visualized, but simultaneously big enough to limit the short-circuit current and thus protecting the motor from complete failure when the short is introduced. To reduce the thermal problems, the laboratory tests were carried out at a reduced voltage of $220 \mathrm{~V}$ line.

Fig. 3 shows the typical stator current Park's Vector pattern corresponding to a healthy motor. This pattern differs slightly from the circular locus expected for ideal conditions because the supply voltage is not exactly sinusoidal [2].

The occurrence of inter-turn short circuits manifests itself in the deformation of the current Park's Vector pattern corresponding to a healthy condition, leading to an elliptic represen-

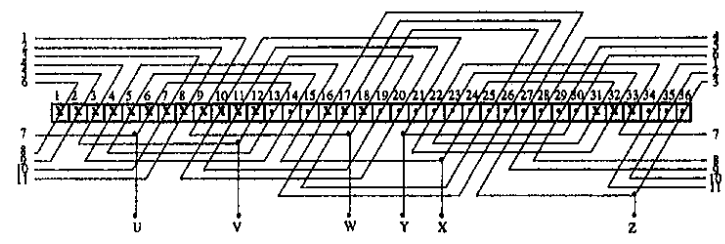

Fig. 1 - Stator winding arrangement.

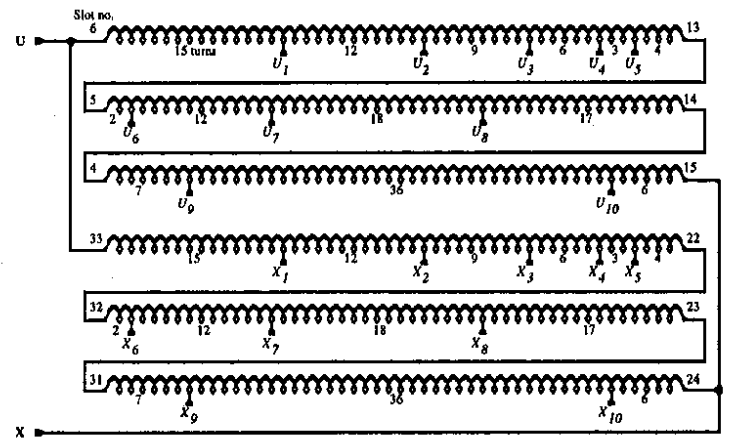

Fig. 2 - Location of the tappings for motor phase $A$. tation whose ellipticity increases with the severity of the fault (Figs. $3-6$ ) and whose major axis orientation is associated to the faulty phase (Figs. $6-8$ ).

Other experimental tests carried out with a Mawdsley Generalised Electrical Machine ${ }^{\otimes}$, connected as a three-phase, 4-pole, induction motor, with a double-layer stator winding series arrangement and rated at $220 / 380 \mathrm{~V}, 1450 \mathrm{rpm}$, lead to similar results.

\section{ON-SITE TESTS}

Field tests were conducted in a power generation plant in order to assess the suitability of the instrumentation system developed, when used in the industrial environment.

These tests were performed on several three-phase, $50 \mathrm{~Hz}$, 4-pole, induction machines, whose rated power is in the range of $30 \mathrm{~kW}$ to $132 \mathrm{~kW}$.

Although no stator winding faults were detected so far on the basis of the first test, the instrumentation system developed proved to be flexible and easy of use.

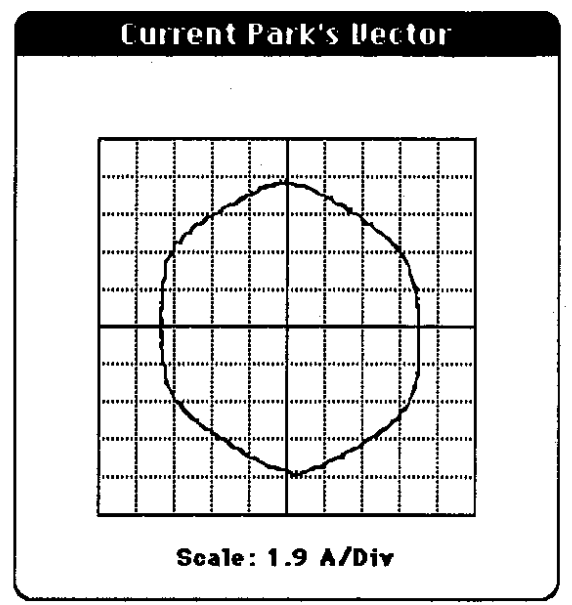

Fig. 3 - Experimental current Park's Vector pattern, corresponding to a healthy motor.

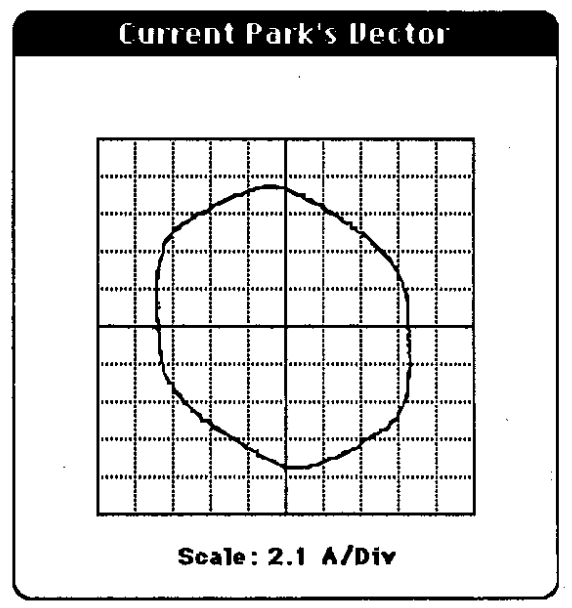

Fig. 4 - Experimental current Park's Vector pattern, for the case of three shorted turns in phase $A\left(U_{4}-U_{5}\right)$. 


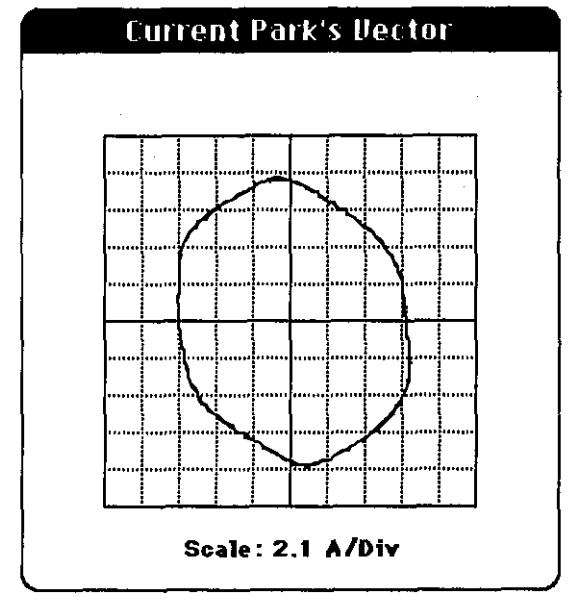

Fig. 5 - Experimental current Park's Vector pattern, for the case of six shorted turns in phase $A\left(U_{3}-U_{4}\right)$.

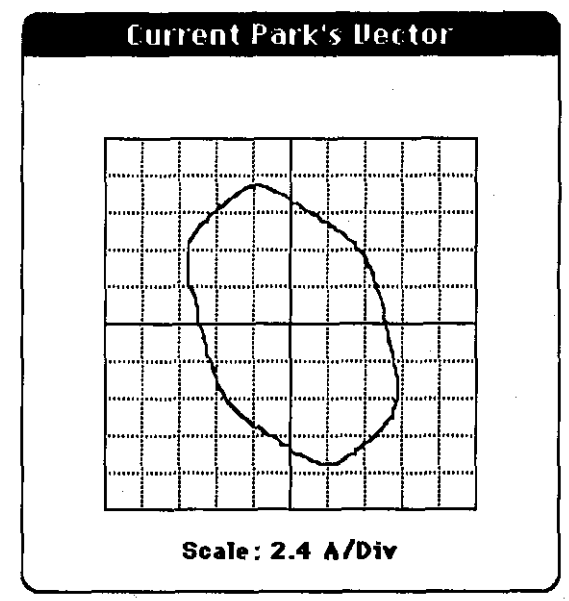

Fig. 6- Experimental current Park's Vector pattern, for the case of eighteen shorted turns in phase $A\left(\mathrm{U}_{7}-\mathrm{U}_{8}\right)$.

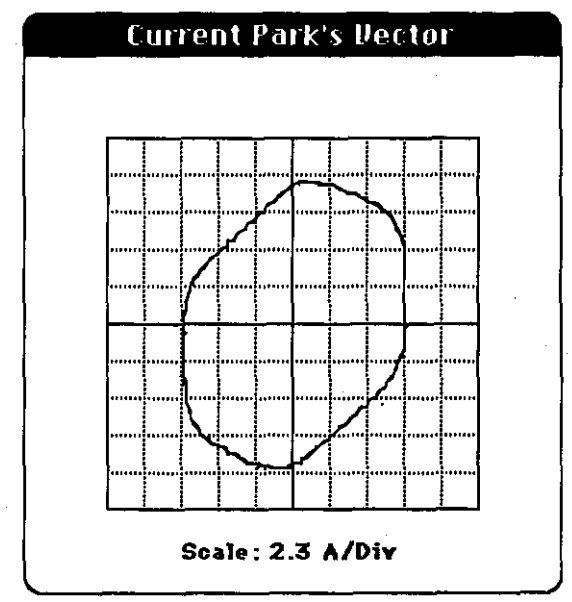

Fig. 7 - Experimental current Park's Vector pattern, for the case of eighteen shorted turns in phase $B\left(\mathrm{~V}_{7}-\mathrm{V}_{8}\right)$.
Current Park's llector

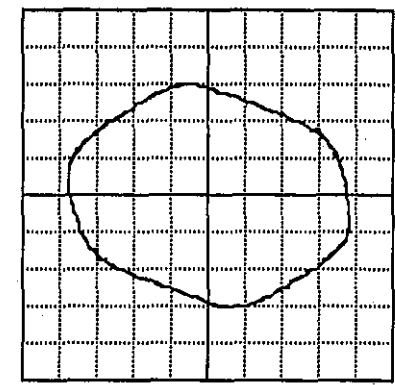

Scale : 2.3 A/Dir

Fig. 8 - Experimental current Park's Vector pattern, for the case of eighteen shorted turns in phase $C\left(\mathrm{~W}_{7}-\mathrm{W}_{8}\right)$.

Further evaluation tests have to be done in the industrial environment, in order to assess the effectiveness of the diagnostic technique developed in the laboratory, when applied to large three-phase induction motors.

\section{CONCLUSION}

This paper introduces a new approach, based on the computer-aided monitoring of the motor current Park's Vector, for diagnosing the occurrence of inter-turn short circuits in the stator windings of operating three-phase induction machines.

The on-line diagnosis is based on identifying the appearance of an elliptic pattern, corresponding to the motor current Park's Vector representation, whose ellipticity increases with the severity of the fault and whose major axis orientation is associated to the faulty phase.

Further work is currently in progress concerning the use of this approach for diagnosing also stator winding faults in three-phase synchronous machines.

\section{ACKNOWLEDGMENT}

The authors wish to acknowledge the financial support of the National Science and Technology Research Council of Portugal (JNICT), under Project Number PBIC/C/CEG/2441/ 195.

The contribution of Pego Power Generation Plant, for providing the test motor used in the laboratory tests, is greatly acknowledged and thanks are also expressed to the plant personnel for the assistance given during the on-site testing.

\section{REFERENCES}

[1] A. J. M. Cardoso and E. S. Saraiva, "On-line diagnostics of three-phase induction motors, by Park's Vector," Proceedings of the International Conference on Electrical Machines, held in Pisa, Italy, September 12-14, 1988, vol. III, pp. 231-234.

[2] A. J, M. Cardoso and E. S. Saraiva, "Computer-aided detection of airgap eccentricity in operating three-phase induction motors by Park's Vector Approach," IEEE Trans. Industry Applications, vol. 29, no 5, September/October 1993, pp. 897-901. 
[3] A. J. M. Cardoso, S. M. A. Cruz, J. F. S. Carvalho and E. S. Saraiva, "Rotor cage fault diagnosis in three-phase induction motors, by Park's Vector Approach," Conference Record of the 1995 IEEE Industry Applications Society Annual Meeting, held in Orlando, Florida, USA. October 8-12, 1995, vol. I, pp. 642-646.

[4] A. J. M. Cardoso, Fault Dlagnosis in Three-Phase Induction Motors, (in Portuguese), Coimbra Editora (ISBN 972-32-0452-5), 1991.

[5] A. H. Bonnett and G. C. Soukup, "Cause and analysis of stator and rotor failures in three-phase squirrel-cage induction motors," IEEE Trans. Industry Applications, vol. 28, no 4, July/August 1992, pp. 921-937.

[6] W. T. Thomson and C. J. McRae, "On-Line current monitoring to detect inter-turn stator winding faults in induction motors, "Proceedings of the 24th Universities Power Engineering Conference, held in Belfast, September 1989.

[7] R. A. Leonard and W. T. Thomson, "Vibration and stray flux monitoring for unbalanced supply and inter-turn winding fault diagnosis in induction motors, "British Journal of Non-Destructive Testing. July 1986, pp. 211-215.

[8] W. Rams, J. Rusek and J. Skwarczynski, "Stator yoke elliptic deformations of ac machines as winding fault indicator," Proceedings of the International Conference on Electrical Machines, held in Manchester, UK, September 15-17, 1992, vol. 3, pp. 1304-1308.

[9] J. Penman, H. G. Sedding, B. A. Lloyd and W. T. Fink, "Detection and location of inter-turn short circuits in the stator windings of operating motors," IEEE Trans, Energy Conversion, vol. 9, no 4, December 1994, pp. 652-658.

[10] J. Sottile and J. L. Kohler, "An on-line method to detect incipient failure of turn insulation in random-wound motors," IEEE Trans. Energy Conversion, vol. 8, no 4, December 1993, pp. 762-768.

\section{BIOGRAPHIES}

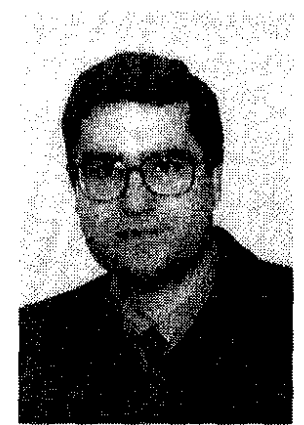

A. J. Marques Cardoso (S'89, A'95) was born in Coimbra. Portugal, on August 21, 1962. He received the E. E. Diploma and the Dr. Eng. degree from the University of Coimbra in 1985 and 1995, respectively.

He has been with the University of Coimbra since 1985 , where he is currently an Assistant Professor in the Department of Electrical Engineering and Director of the Electrical Machines Laboratory. His teaching interests cover electrical machines and power electronics and his research interests are focused on condition monitoring and diagnostics of electrical machines and drives. $\mathrm{He}$ has published a book entitled Fault Diagnosis in Three-Phase Induction Motors (in Portuguese) and more than 30 papers in technical journals and conference procedings.
Dr. Marques Cardoso is actively involved, as an expert, in the field of standardisation on condition monitoring and diagnostics, both at a national and international level, where he has been acting as a convenor of ISO/TC 108/SC 5 Advisory Group C (Condition monitoring of electrical motors and generators, for the purposes of diagnostics) and member of several Working Groups of ISO, JEC and CEN.

He was appointed member of the Overseas Advisory Panel of Condition Monitoring and Diagnostic Technology, a former journal published by the British Institute of Non-Destructive Testing, now incorporated into Insight and he was also a founder member of the European Consortium for Research on Condition Monitoring of Electrical Systems and Drives.

Dr. Marques Cardoso is a member of the New York Academy of Sciences, the European Power Electronics and Drives Association (EPE) the Electrical Machines and the Industrial Drives Committees of the IEEE/IAS, the Portuguese Federation of Industrial Maintenance (APMI) and a senior member of the Portuguese Engineers Association (ODE).

He has been listed in Who's Who in the World, BEST Europe, among others.

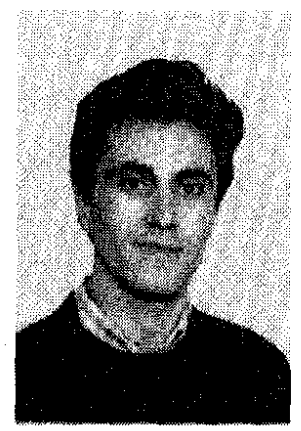

Sérgio M. A. Cruz (S'96) was born in Coimbra, Portugal, on June 19,1971 . He received the E. E. Diploma in 1994, from the University of Coimbra, where he is currently a M.Sc. student and Teaching Assistant in the Department of Electrical Engineering.

His current research interests are on fault diagnosis in electrical machines. He has published 5 papers on this subject.

Mr. Cruz is member of the Portuguese Federation of Industrial Maintenance (APMI) and of the Portuguese Engineers Association (ODE).

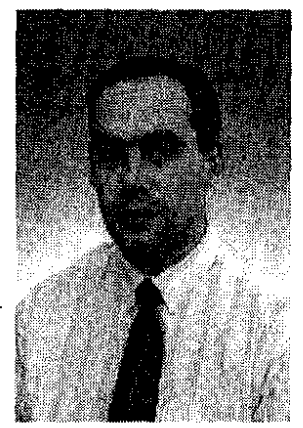

Davide S. B. Fonseca was born in Castelo Branco, Portugal, on December 23, 1972 He received the E. E. Diploma from the University of Coimbra, Coimbra, Portugal, in 1996.

$\mathrm{He}$ is currently with Delphi Packard Electric Systems, Castelo Branco, Portugal. 